\title{
AN ALBUMIN REQUIREMENT FOR FERTILIZATION OF MOUSE EGGS IN VITRO
}

\author{
P. C. HOPPE AND W. K. WHITTEN \\ The Jackson Laboratory, Bar Harbor, Maine 04609, U.S.A.
}

(Received 12th March 1974)

A modified Krebs-Ringer bicarbonate solution containing bovine serum albumin (BSA) supports fertilization in vitro of mouse eggs by spermatozoa taken from the uterus (Whittingham, 1968; Cross \& Brinster, 1970) or the cauda epididymidis (Miyamoto \& Chang, 1972; Hoppe \& Pitts, 1973). Human, rabbit or equine serum albumin could be substituted for BSA (Miyamoto \& Chang, 1973). Though Miyamoto \& Chang (1973) noted sperm penetration of low percentages of mouse eggs in vitro in the presence of a chemically defined medium with added lactate or pyruvate, no significant fertilization has been reported to occur in the absence of albumin.

Further investigations of the requirements for albumin, which are presented in this report, indicate that fertilization occurred efficiently in media supplemented with BSA in concentrations lower than those reported by others. Bovine serum albumin essentially free of fatty acids or albumin from hens eggs also supported fertilization by spermatozoa from the cauda epididymidis. Fertilization did not occur in a chemically defined tissue culture medium or the medium of Whitten (1971) supplemented with polyvinylpyrrolidone (PVP) or with PVP and amino acids.

The procedures used for fertilization of mouse eggs in vitro using epididymal spermatozoa have been reported previously (Hoppe \& Pitts, 1973). Whitten's medium $(0.5 \mathrm{ml})$ containing various preparations of bovine albumin (Pentex), egg albumin (Sigma) or PVP (mol. wt 40,000: Mann Research Lab. Inc.) either alone or in combination with amino acids (Sigma), or Waymouth's tissue culture medium (No. MB 752/1, Grand Island Biological Co.) were pipetted into embryological watchglasses and $2 \mathrm{ml}$ paraffin oil were added. The watchglasses were prepared in the evening and allowed to equilibrate overnight at $37^{\circ} \mathrm{C}$ with a gas phase composed of $5 \% \mathrm{CO}_{2}, 5 \% \mathrm{O}_{2}$ and $90 \%$ $\mathrm{N}_{2}$. The following morning, eggs were collected 2 to $3 \mathrm{hr}$ after natural ovulation from $F_{1}$ hybrid females $(\mathrm{SJL} / \mathrm{Wt} \times \mathrm{C} 57 \mathrm{BL} / 10 \mathrm{Wt}$ ) which had been selected in pro-oestrus by the visual appearance of the vagina (Champlin, Dorr \& Gates, 1973) the previous evening. Ampullae were punctured to release the eggs into Whitten's medium containing hyaluronidase $(1 \mathrm{mg} / \mathrm{ml})$ to remove the cumulus cells. The eggs were then pooled and washed three times in 1-ml aliquots of medium that was to be used for fertilization and ten to twenty eggs were pipetted into each watchglass. After removal of the cumulus cells, the eggs were washed so that the proteins in the oviducal fluid could not interfere with experiments aimed at investigating requirements for fertilization in vitro. 
The right and left cauda epididymidis and ductus deferens from an $F_{1}$ hybrid male were minced in $1 \mathrm{ml}$ medium under $2 \mathrm{ml}$ paraffin oil and approximately $30 \mu \mathrm{l}$ of the sperm suspension was mixed with the eggs in each watchglass. The sperm suspensions were prepared in the respective media used for fertilization. The gametes were incubated at $37^{\circ} \mathrm{C}$ in the gas phase described above with shaking for 5 to $6 \mathrm{hr}$ in various media. The eggs were then cultured in glass test-tubes containing Whitten's medium supplemented with $3 \mathrm{mg}$ crystalline $\mathrm{BSA} / \mathrm{ml}$ and the number of eggs cleaving and subsequently developing to blastocysts was determined.

Initial experiments indicated that significant proportions of the eggs were fertilized when the concentration of crystalline BSA was $0.3 \mathrm{mg} / \mathrm{ml}$ or greater (Table 1). When the BSA concentration was increased to 3 and $30 \mathrm{mg} / \mathrm{ml}$, 90 and $98 \%$ of the eggs were fertilized respectively. Fraction V BSA or crystalline BSA from which fatty acids were removed by charcoal absorption (Chen, 1967) supported fertilization as effectively as the standard crystalline BSA.

Table 1. Effect of various albumins on fertilization in vitro of mouse eggs without cumulus cells

\begin{tabular}{l|c|c|c|c}
\hline \multicolumn{1}{c|}{ Source of albumin } & $\begin{array}{c}\text { Concentration } \\
(\mathrm{mg} / \mathrm{ml})\end{array}$ & No. of ova $\dagger$ & $\%$ Fertilized & $\begin{array}{c}\text { \% Fertilized eggs } \\
\text { developing to blastocysts } \\
\text { in culture }\end{array}$ \\
\hline Crystalline BSA & 0 & 89 & 8 & 100 \\
& $0 \cdot 03$ & 86 & 4 & 67 \\
& $0 \cdot 3$ & 91 & 59 & 94 \\
Fatty acid-free BSA & $3 \cdot 0$ & 94 & 90 & 94 \\
Fraction V BSA & $3 \cdot 0$ & 87 & 98 & 99 \\
Crystalline egg albumin & $3 \cdot 0$ & 74 & 98 & $81^{*}$ \\
& 10 & 54 & 17 & 100 \\
& 20 & 59 & 51 & 97 \\
\hline
\end{tabular}

* One culture tube with twelve embryos was contaminated.

$\dagger$ Six observations per treatment.

Polyvinylpyrrolidone has been used for egg culture in our laboratory (Cholewa \& Whitten, 1970; P. G. Hoppe, unpublished observations). Gwatkin \& Haidri (1973) also used PVP in combination with amino acids (L-glutamine, $14.6 \mathrm{mg} / \mathrm{ml}$; L-isoleucine, $2.6 \mathrm{mg} / \mathrm{ml}$; L-methionine, $0.8 \mathrm{mg} / \mathrm{ml}$; L-phenylalanine, $1.6 \mathrm{mg} / \mathrm{ml}$ ) for the maturation of hamster oocytes. These experiments suggest that PVP might substitute for BSA for fertilization of eggs in vitro, but Whitten's medium supplemented with 0.1 or $1.0 \mathrm{mg} \mathrm{PVP} / \mathrm{ml}$ did not support fertilization. Further supplementation of the PVP-containing medium with the amino acid composition used by Gwatkin \& Haidri (1973) or a mixture of amino acids which approximated to those present in BSA (Brinster, 1965) at a concentration of $3 \%$ also failed to support fertilization. Similarly, fertilization did not occur in Waymouth's chemically defined tissue culture medium. After incubation of the gametes for 5 to $6 \mathrm{hr}$ in the above media, examination of the eggs did not reveal the presence of second polar bodies or pronuclei. 
Supplementation of Whitten's medium with crystalline egg albumin $(10 \mathrm{mg} /$ ml) resulted in the fertilization of a significant number of eggs (Table 1). The results, however, were quite variable; less fertilization occurred when concentrations of egg albumin were 5 or $20 \mathrm{mg} / \mathrm{ml}$ than when the concentration was $10 \mathrm{mg} / \mathrm{ml}$. These results indicate that egg albumin can support fertilization in vitro but with approximately half of the efficiency of BSA. This is the first report of the fertilization of mammalian eggs in a simple medium containing a non-mammalian protein.

The proportion of fertilized eggs developing to blastocysts in culture did not differ from that reported earlier (Hoppe \& Pitts, 1973) and was not affected by the use of different albumin preparations during fertilization (Table 1). Two of three eggs fertilized in medium containing crystalline BSA $(0.03 \mathrm{mg} /$ $\mathrm{ml}$ ) developed to blastocysts and the low percentage (67\%) in development shown in Table 1 is due to the small sample size. One culture tube containing twelve eggs fertilized in medium containing Fraction V BSA was contaminated and the embryos died before blastulation.

The results of this study agree with the findings of Cross \& Brinster (1970) and of Miyamoto \& Chang (1973) concerning the necessity of albumin for fertilization in vitro of mouse ova. The former investigators obtained optimal fertilization rates in medium containing $\mathrm{BSA}$ at a concentration of $30 \mathrm{mg} / \mathrm{ml}$ and the latter workers used bovine, equine, rabbit and human serum albumin at concentrations of 10 to $20 \mathrm{mg} / \mathrm{ml}$. In the present study, significantly more eggs were fertilized with lower BSA concentrations than those used by Cross \& Brinster (1970), who also removed cumulus cells with hyaluronidase and washed freshly ovulated eggs three times before attempting fertilization in media containing different BSA concentrations. The influence of oviducal fluids was eliminated in these studies. The oxygen concentration used in our study is low in comparison with that in the mixture of $5 \% \mathrm{CO}_{2}$ in air used by Cross \& Brinster (1970) and by Miyamoto \& Chang (1973) and this fact may be related to the effectiveness of relatively low concentrations of BSA in our experiments (Whitten, 1971). The reason for the low fertilization rate obtained with egg albumin relative to that obtained with BSA is unknown. The function of albumin during fertilization may be to stabilize spermatozoa and egg membranes, to chelate toxic inorganic ions, or to promote carbon dioxide transport. Our attempts to achieve fertilization in vitro using a chemically defined medium have as yet been unsuccessful.

This research was supported by NIH Research Grant HD-04083 and Contract HD-72-2740 from the National Institute of Child Health and Human Development. We thank Mr Stetson Carter and Mr Darrold Dorr for technical assistance and Dr Andrew A. Kandutsch for valuable criticism of the manuscript. The Jackson Laboratory is fully accredited by the American Association for Accreditation of Laboratory Animal Care.

\section{REFERENCES}

BRINSTER, R. L. (1965) Studies in the development of mouse embryos in vitro. III. The effect of fixednitrogen source. F. exp. Zool. 158, 69. 
Champlin, A. K., Dorr, D. L. \& Gates, A. H. (1973) Determining the stage of the estrous cycle in the mouse by the appearance of the vagina. Biol. Reprod. 8, 491.

Chen, R. F. (1967) Removal of fatty acids from serum albumin by charcoal treatment. 7. biol. Chem. 242, 173.

Cholewa, J. A. \& Whitren, W. K. (1970) Development of two-cell mouse embryos in the absence of a fixed-nitrogen source. 7. Reprod. Fert. 22, 553.

Cross, P. C. \& Brinster, R. L. (1970) In vitro development of mouse oocytes. Biol. Reprod. 3, 298.

GWATKIN, R. B. L. \& HaidRI, A. A. (1973) Requirement for the maturation of hamster oocytes in vitro. Expl Cell Res. 76, 1.

Hoppe, P. C. \& Pitrs, S. (1973) Fertilization in vitro and development of mouse ova. Biol. Reprod. 8, 420.

Mryamoto, H. \& Chang, M. G. (1972) Development of mouse eggs fertilized in vitro by epididymal spermatozoa. F. Reprod. Fert. 30, 135.

Mryamoto, H. \& Chang, M. C. (1973) The importance of serum albumin and metabolic intermediates for capacitation of spermatozoa and fertilization of mouse eggs in vitro. 7 . Reprod. Fert. 32, 193.

WhitTen, W. K. (1971) Nutrient requirement for the culture of pre-implantation embryos in vitro. Adv. Biosci. 6, 129.

Whittingham, D. F. (1968) Fertilization of mouse eggs in vitro. Nature, Lond. 220, 592. 